teers were eating plastic particles and when they were eating bran.

\section{Comment}

Supplementing the daily diet of healthy volunteers with $15 \mathrm{~g}$ inert plastic particles increased the stool mass by nearly three times the mass of plastic ingested, increased the frequency of defecation, and reduced the transit time through the whole gut. These effects may be caused by mechanical stimulation of mucosal receptors as stroking the intestinal epithelium can induce secretion and stimulate peristalsis. ${ }^{4}$ The enteric nervous reflexes that induce these phenomena may be activated by direct stimulation of sensory nerve endings or through release of transmitters, such as histamine, serotonin, or prostaglandins, from mucosal or submucosal cells.

The similarity in the results we obtained during ingestion of coarse bran and plastic "fibre" and the observation that the laxative action of coarse bran is greater than that of fine bran suggest that at least part of the action of coarse wheat bran may also be mediated by mechanical stimulation of mucosal receptors. We think that our results may add a new perspective to the laxative action of bran, which could lead to the development of new fibre products.

Riottot M, Saquet E, Leprince C. Effect of wheat bran upon gastrointestinal transit in germ free and conventional rats. Digestion 1984;29:37-41.

2 Davies GJ, Crowder M, Reid B, Dickerson JWT. Bowel function measurements of individuals with different eating patterns. Gut 1986;27:164-9.

3 Cummings JH, Jenkins DJA, Wiggins HS. Measurement of the mean transit time of dietary residue through the human gut. Gut 1976;17:210-8.

4 Beubler E, Juan H. PGE-released blood flow and transmucosal water movement after mechanical stimulation of the rat jejunal mucosa. Naunyn Schmeideberg's Arch Pharmacol 1978;305:91-5.

5 Hukuhura T, Miyake T. The intrinsic reflexes in the colon. Fapanese fournal of Physiology 1959;9:49-55.

(Accepted 19 \{uly 1988)

\title{
Importance of scrotal ultrasonography in gynaecomastia
}

\section{Gerard S Conway, Tom MacConnell, Geoffrey Wells, Stefan D Slater}

Endocrine Unit, Cobbold Laboratories, Middlesex Hospital, London W1N 8AA

Gerard S Conway, MRCP, research registrar in endocrinology

\section{Victoria Infirmary,} Glasgow G42 9TY Tom MacConnell, MRCP, registrar in medicine Geoffrey Wells, FRCS, registrar in urology

Stefan D Slater, MD, consultant physician

Correspondence to: Dr Conway.
Failure to find an underlying cause for gynaecomastia is common. A testicular origin for feminisation is often excluded on clinical examination. We describe two patients with gynaecomastia and raised serum oestradiol concentrations who were found to have testicular tumours on ultrasonography of the scrotum, which were not detectable clinically.

\section{Case reports}

Two men (aged 28 and 26) presented with symmetrical gynaecomastia of four years' and six months' duration respectively. The second patient had had bilateral orchidoplexy at age 10 , and his right testis was undescended but easily palpable in the superficial inguinal pouch. Both patients had undergone normal development in puberty with no gynaecomastia. Neither was taking any drugs, and both were otherwise well. The distribution of body hair was normal in both, although the first patient shaved only every second day, and the testes were smooth and regular but small.

Investigations showed low serum testosterone concentrations $(5 \cdot 0-7 \cdot 0 \mathrm{nmol} / 1$ and $5 \cdot 6-11 \cdot 0 \mathrm{nmol} / \mathrm{l}$ respectively, normal range $11-36 \mathrm{nmol} / 1$ ) and increased serum oestradiol concentrations $(277-410 \mathrm{pmol} / /$ and $300-430 \mathrm{pmol} / 1$ respectively, normal range $<200$ $\mathrm{pmol} / \mathrm{h})$. The corresponding serum concentrations of luteinising hormone $(6 \cdot 1-6 \cdot 3 \mathrm{U} / 1$ and $6 \cdot 0-10 \cdot 0 \mathrm{U} / 1$, normal range $2 \cdot 0-8 \cdot 6 \mathrm{U} / \mathrm{I}$ ) and follicle stimulating hormone (1.4-2.1 $\mathrm{U} / \mathrm{l}$ and 1·7-3.3 $\mathrm{U} / \mathrm{l}$, normal range $1 \cdot 0-4 \cdot 5 \mathrm{U} / \mathrm{l}$ ) were normal. No abnormalities were detected in leucocyte karyotypes. Ultrasonography (and in the first patient computed tomography) of the adrenal glands yielded normal results. In both men ultrasonography of the scrotum disclosed a $1 \mathrm{~cm}$ mass in the lower pole of the right testis, which could not be felt (figure). In the first patient the left testicle was normal apart from its generally hypoechoic texture; in the second no abnormality was detected in the left testis. The tumours were confirmed at operation, and right orchidectomies were performed. Tumours of the Leydig cells were identified microscopically.

After operation the serum oestradiol concentrations fell to $105 \mathrm{pmol} / \mathrm{l}$ and $210 \mathrm{pmol} / \mathrm{l}$ at three and five weeks respectively, with a rebound rise of luteinising hormone (48.6 U/1 and $21.0 \mathrm{U} / \mathrm{l})$, follicle stimulating hormone (12.0 U/1 and 16.0 U/l), and testosterone $(20.8 \mathrm{nmol} / 1$ and $18.4 \mathrm{nmol} / \mathrm{l})$ concentrations. Repeat ultrasonography of the left testicle in the first patient showed normal echo texture. He subsequently started shaving every day. The gynaecomastia did not subsequently improve in either case. Owing to the first patient's longer history fibrosis may prevent regression and plastic surgery may be required. ${ }^{1}$

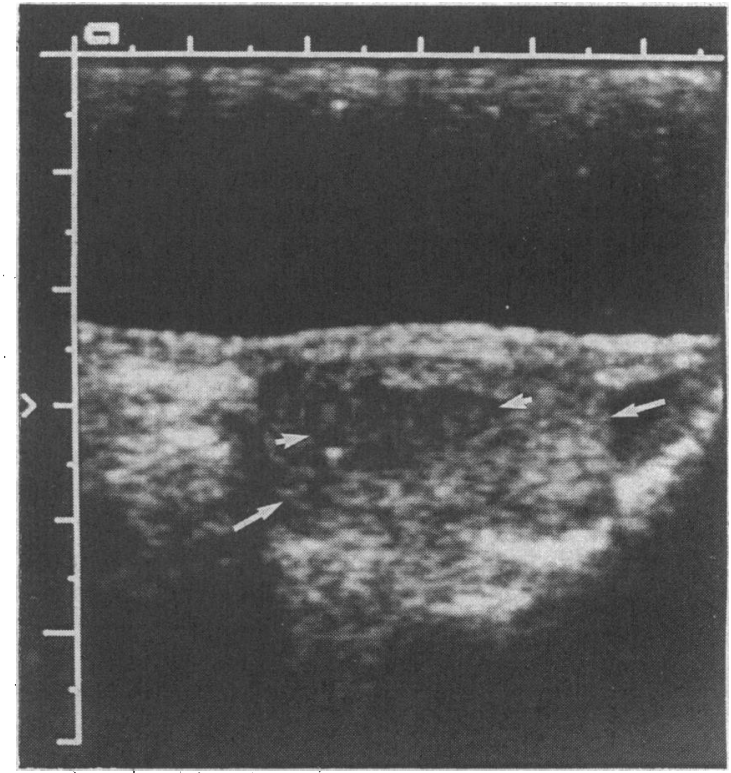

Ultrasonogram of testicle (large arrows) containing tumour of Leydig cells (small arrows)

\section{Comment}

Identification of occult tumours of the testis by ultrasonography is an important but underused technique in investigating gynaecomastia. Feminising tumours of Leydig cells have previously been detected only by clinical examination. Thus in the largest review of gynaecomastia in all 37 cases caused by interstitial cell tumours the testicular mass was palpable. ${ }^{2}$ Tumours of Leydig cells accounted for $1 \cdot 2 \%$ of all the testicular tumours and about $20 \%$ of them caused gynaecomastia. Less than $10 \%$ are malignant, in contrast to feminising adrenocortical tumours, which are usually malignant. Occult testicular tumours have been diagnosed by ultrasonography in four patients. ${ }^{3.5}$ An evaluation of the diagnostic criteria for tumours of Leydig cells has shown that whereas the tumour was localised by ultrasonography in all 12 patients scanned, including two with non-palpable lesions, the serum 
oestradiol concentration and the ratio of serum oestradiol concentration to serum testosterone concentration were raised in only nine of the 14 patients studied, and the serum testosterone concentration was low in only five. Scrotal ultrasonography therefore seems to be the most accurate investigation and its increased use in patients with gynaecomastia may reduce the large proportion of idiopathic cases.

The hypoechoic texture seen in the contralateral testis in the first patient can be explained by tubular atrophy, fibrosis, loss of Leydig cells, and hypospermatogenesis that commonly occurs as a result of an increased ratio of oestrogen to androgen concentrations. ${ }^{2}$ Recognition of these textural changes may be valuable in diagnosis in patients without gynaecomastia but with otherwise unexplained loss of libido or potency.
We thank Professor H S Jacobs and Mr J Pryor for permission to report on their patient (case 1), and Dr A Coral of the department of ultrasonography of Middlesex Hospital for his skill and for the figure.

1 Nicholis GL, Modlinger RS, Gabrilove JL. A study of the histopathology of human gynecosin 7 Clin Endocrinol Metab 1971:32:173.

2 Gabrilove JL, Nicolis GL, Mitty HA, Sohval AR. Feminizing interstitial cell tumour of the testis: personal observations and a review of the literature. Cancer 1975;35:1184-202

3 Hendry WS, Garvie WHH, Ah-see AK, Bayliss AP. Ultrasonic detection of occult testicular neoplasms in patients with gynaecomastia. $\mathrm{Br} \mathcal{f}$ Radiol 1984;57:571-2.

4 Emory TH, Charboneau JW, Randall RV, Scheithauer BW, Grantham JG. Occult testicular interstitial-cell tumour in a patient with gynaecomastia: ultrasonic detection. Radiology 1984;151:474.

5 Kuhn JM, Mahoudeau JA, Billaud L, et al. Evaluation of diagnostic criteria for Leydig cell tumours in adult men revealed by gynaecomastia. Clin Endocrinol 1987;26:407-16.

(Accepted 22 fuly 1988)
Department of Neurology,

Austin Hospital,

Heidelberg, Victoria 3084, Australia

C C Rowe, BM, stroke research

fellow

G A Donnan, FRACP, staff neurologist

P F Bladin, FRACP, director

Correspondence to: $\mathrm{Dr}$ Donnan.

\section{Intracerebral haemorrhage: incidence and use of computed tomography}

\section{C Rowe, G A Donnan, P F Bladin}

The incidence of primary intracerebral haemorrhage fell between 1950 and $1975 .^{\prime}$ We analysed admissions to this hospital's stroke unit from 1978 to 1985 to see whether the incidence of intracerebral haemorrhage bore any relation to the use of computed tomography.

\section{Patients, methods, and results}

The stroke unit was formed in 1977 to receive all patients presenting with suspected stroke or transient ischaemic attack. Computed tomography was performed whenever possible, and the proportion of patients scanned rose as access to facilities improved. Data accumulated prospectively on all patients (2537) were examined to determine the effect of computed tomography on the diagnosis of intracerebral haemorrhage and were analysed by the $\chi^{2}$ test for trend and Pearson correlation coefficients. In addition the volumes of the haemorrhages were calculated by placing a grid over the scan, each square in the grid representing $1 \mathrm{~cm}^{2}$ of brain. The number of squares that were more than half occupied were totalled, and the resulting number was multiplied by the thickness of the tomographic slice. This was repeated for all slices showing haemorrhage. A haemorrhage of $10 \mathrm{ml}$ or less was classed as small. Many scans obtained in 1978-80 were not available, and the size of haemorrhage (small $v$ medium or large) was then determined from the radiologist's report and the unit's records. A comparison of these methods showed that interpretation of the report tended to overestimate the number of small haemorrhages. Hence a bias in favour of more small haemorrhages for 1978-80 might be expected. Diagnosis of haemorrhages without computed tomography was based on findings at necropsy or the clinical features of a sudden rapid deterioration associated with headache, vomiting, and impairment of consciousness.

The figure shows that admissions for intracerebral haemorrhage rose significantly from $3.8 \%$ in 1978 to $8.6 \%$ in 1985 ( $p<0.001, \chi^{2}$ test for trend) with a peak of $12.3 \%$ in 1983 and that use of computed tomography increased from half of all admissions to $95 \%(\mathrm{p}<0.001$, $\chi^{2}$ test for trend). A close correlation between these two events was found (Pearson correlation $r=0.77$, $\mathrm{p}=0.027)$. A greater correlation was found between

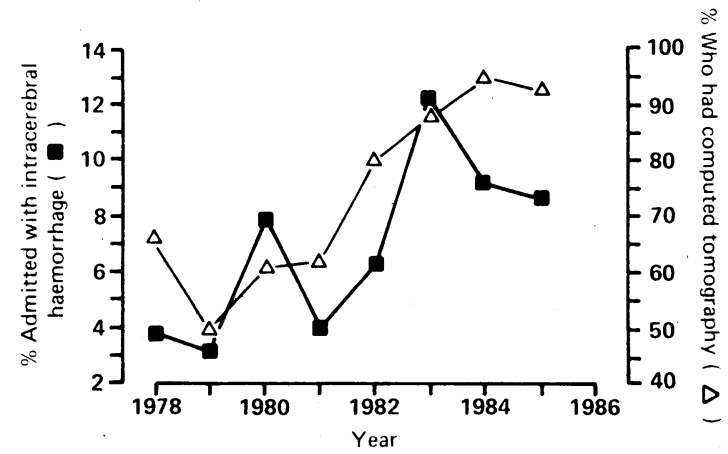

Percentage of patients admitted each year to stroke unit with intracerebral haemorrhage (total $=186$ ) and percentage who had computed tomography

use of computed tomography and incidence of small haemorrhage $(r=0 \cdot 82, p=0 \cdot 012)$. At the same time mortality in hospital for patients with intracerebral haemorrhage fell significantly from $55 \%$ to $29 \%$ $\left(\mathrm{p}<0.05, \chi^{2}\right.$ test for trend) and correlated inversely with increasing use of computed tomography $(r=-0.92)$. In contrast, the annual incidence of haemorrhage among those not examined with computed tomography did not change significantly $\left(\mathrm{p}<0 \cdot 2, \chi^{2}\right.$ test for trend), and this group had a $94 \%$ mortality in hospital. Annual admissions to the stroke unit rose during the study, but no significant changes in the characteristics of the patients were found.

\section{Comment}

We found a strong correlation between the use of computed tomography and the incidence of intracerebral haemorrhage, particularly small haemorrhages. Garraway et al noted that the proportion of strokes due to haemorrhage in the population of Rochester, Minnesota, doubled after 1975 and suggested that this was due to the introduction of computed tomography. ${ }^{2}$ We conclude that use of computed tomography also explains the apparent rise in the incidence of haemorrhage in our study and provide evidence to support this. The falling mortality reflects the fact that more small, benign haemorrhages were detected, and recent studies have shown that outcome, including survival, correlates closely with the size of haemorrhage. ${ }^{3-5}$

Two important conclusions may be drawn from our data. Firstly, an imaging procedure such as computed tomography is essential to establish the diagnosis of intracerebral haemorrhage in vivo. Secondly, any comparative or longitudinal study of the incidence of this and other types of stroke, based either in the community or in hospital, must use a reliable neuroimaging technique in a high and constant 